\title{
The proportion of unhealthy foodstuffs children are exposed to at the checkout of convenience supermarkets
}

\author{
Jason A Horsley ${ }^{1, *}$, Katie AR Absalom², Evie M Akiens², Robert J Dunk ${ }^{2}$ and \\ Alice M Ferguson ${ }^{2}$ \\ 'School of Health and Related Research, University of Sheffield, Regent Court, 30 Regent Street, \\ Sheffield S1 4DA, UK: ${ }^{2}$ The Medical School, University of Sheffield, Sheffield, UK
}

Submitted 1 August 2013: Final revision received 13 November 2013: Accepted 19 December 2013: First published online 22 January 2014

\begin{abstract}
Objective: To investigate the proportion of foods that are unhealthy to which children are exposed at the checkout of convenience supermarkets.

Design: We performed a cross-sectional survey of foodstuffs displayed at the checkout. Products displayed at or below children's eye-level were designated as healthy, unhealthy or unclassifiable using the Food Standards Agency's scoring criteria.

Setting: Thirteen convenience supermarkets from the three leading UK supermarket chains were selected on the basis of proximity to the town hall in Sheffield, England.

Subjects: Convenience supermarkets were defined as branches of supermarket chains that were identified as being other than superstores on their company's store locator website.

Results: In almost all of the convenience supermarkets surveyed, the main healthy product on display was sugar-free chewing gum. On average, when chewing gum was not included as a foodstuff, $89 \%$ of the products on display at the checkouts of convenience supermarkets were unhealthy using the Food Standards Agency's criteria. One store was a notable outlier, providing only fruit and nuts at its checkout.

Conclusions: The overwhelming majority of products to which children are exposed at the convenience supermarket checkout are unhealthy. This is despite all the supermarket chains surveyed having signed up to the UK Government's 'responsibility deal'.
\end{abstract}

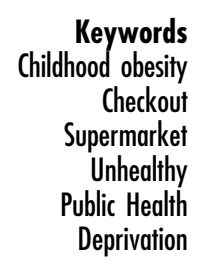

Obesity results from an imbalance between energy intake and expenditure, although there are numerous influences that impact an individual's chances of becoming obese ${ }^{(1)}$. These include his/her genetic, physiological and psychological variables, as well as the physical, social and economic environment he/she inhabits ${ }^{(1)}$. Childhood obesity rates in the UK have risen dramatically over the last two to three decades ${ }^{(2-4)}$. In obese children there is evidence that poor diet precedes the lack of physical activity $^{(5)}$. Childhood obesity is associated with an increased risk of obesity in adulthood ${ }^{(6)}$. Obesity in childhood directly affects physical and mental health ${ }^{(7,8)}$. Subsequent obesity in adulthood increases risk of type 2 diabetes, CVD and many forms of cancer ${ }^{(7,8)}$. The WHO has concluded that heavy marketing of processed energydense foodstuffs to children is a 'probable' causal factor for childhood obesity ${ }^{(9)}$.

Children are a significant market for retailers of processed foodstuffs and budgets dedicated to advertising to children have grown exponentially in the last three decades ${ }^{(10)}$. Children are often naive to sophisticated marketing techniques ${ }^{(11)}$. They also influence parents' purchases through 'pester power' ${ }^{\text {(12) }}$ and previous research has shown that the number of attempts children make to influence parents' purchasing decisions peaks in the 3-5 year age group ${ }^{(13)}$. This age corresponds to a developmental stage at which children are at their most egocentric and are least able to delay gratification, yet depend on parents for gratification of their desires ${ }^{(13)}$.

The checkout represents an area all shoppers must pass through, so displays of highly desirable, energy-dense foodstuffs are an unavoidable exposure. Studies in supermarkets in Australia and America have shown that the checkout is a common site of exposure to unhealthy foods for both children and adults ${ }^{(14-16)}$. Children can exercise 'pester power' in the area immediately surrounding the checkout and this has been recognised as an unwanted problem for parents ${ }^{(17)}$.

Convenience supermarkets are typically smaller versions of the traditional superstores, offering longer opening hours and often based in more convenient inner-city locations. Figures produced by The Institute of 
Grocery Distribution ${ }^{(18)}$ show that sales through convenience stores increased by $4.6 \%$ in 2012 , and convenience stores now represent $20 \cdot 8 \%$ of the UK food and beverage market. They state that 'Tesco Express and Sainsbury's Local [are] both displaying impressive estate growth ${ }^{\text {(18); }}$; however, the total number of convenience stores in the UK has declined, mostly through a decline in the number of independent stores ${ }^{(18)}$. The current trend is for this type of store to be servicing a larger proportion of the market but for the growth of the larger chains to be at the expense of smaller independent operators.

We were unable to find much academic research on the exposure of children to unhealthy foods at supermarket checkouts. There have been a few campaign groups that have tried to address the issue, most notably in the UK the Food Commission's 'Chuck Snacks off the Checkout!' campaign. This group attempted to survey the degree to which unhealthy products were displayed at supermarket checkouts, in response to concerns from parents. The survey found that unhealthy foods were prevalent on supermarket checkouts in $2003^{(19)}$, and despite a public campaign many retailers still displayed snack foods on their checkouts in $2005^{(20)}$. The campaign seems to have tailed off, although a repeat survey in 2009 suggests that some of the major supermarket brands were reducing snacks on the checkout in big stores, although the authors noted that convenience stores were not following this trend ${ }^{(21)}$.

The majority of published international research in this area comes from Australia. Previous Australian research has shown that some products can be specifically considered as being marketed to children because of the use of cartoon characters or novelty packaging, and that the majority of products using these techniques are unhealthy ${ }^{(22)}$. Australian research has also demonstrated that children commonly request unhealthy foods during supermarket trips and that $70 \%$ of parents purchased at least one of the food items their children requested ${ }^{(23)}$.

Research examining the link between deprivation and the proportion of unhealthy foods at the checkout has found mixed results. At an individual level, an Australian study has shown that shoppers from a lower socio-economic status background are more likely to purchase 'non-core' foods such as chips or sweetened beverages ${ }^{(24)}$, although the study did not examine behaviour at the checkout. Two Australian studies examined the link between area-level deprivation and supermarket displays, finding that in more deprived areas the total amount of shelf space dedicated to unhealthy foods was greater ${ }^{(25)}$ but that the number of prominent displays of snack foods was not related to deprivation ${ }^{(15)}$.

The present study chose to examine the extent to which children are exposed to unhealthy products at the checkout area of these convenience supermarkets in the UK. Sheffield was chosen for the study because it was convenient for the conduct of unfunded research, with all of the researchers being based in Sheffield. Sheffield is a mid-sized urban centre with a population of 551800 in 2011. The main influences on its economy are its industrial sites, as well as a large university and tertiary hospital ${ }^{(26)}$. The stores included in the study were predominantly in urban areas.

\section{Experimental methods}

A survey was carried out between 20 February and 20 March 2012 to determine the extent to which children were exposed to unhealthy products at the checkout area of chain convenience stores. Thirteen stores from the three leading supermarket chains (Tesco, Sainsbury's and Asda) were selected using the supermarket's respective website to identify store locations within a mile of the Sheffield town hall. The timing of data collection was predetermined as this represented a medical student project that had to fit within the restrictions of the academic year.

The checkout was defined as any compulsory area that shoppers would have to pass through to pay for their goods. In convenience/local supermarkets these often had long 'snaking' queues. As we were aiming to measure the exposure of pre-school children to products, only products presented at up to $1 \mathrm{~m}$ off the ground were considered, as this is approximately the height of a 5-year-old child's eye-line ${ }^{(27)}$. This level was chosen recognising that research has shown customers are most likely to purchase products presented at their eye-level ${ }^{(28)}$ and on the assumption that supermarkets would probably choose to market products to children at or below their eye-level. We chose not to adopt definitions from previous studies of products being marketed specifically to children (through the inclusion of cartoon or film characters) ${ }^{(29)}$, as this would underestimate their exposure to products that do not use these images.

Products displayed and their prices were recorded. Non-food products were recorded, but were not included in the analysis of the proportion of healthy food/beverage products. Nutritional information was then entered into a database compiled from either the manufacturer's website or supermarket websites. This information included the product's energy content by weight, and the amount of fat, sugar, protein, fibre and salt per $100 \mathrm{~g}$, as well as the proportion of the product that is made up of fruit, vegetables or nuts. Nutritional values were then used to calculate a value from the Food Standards Agency's (FSA) Nutrient Profiling score ${ }^{(30)}$. This assigns positive points based on energy, salt, sugar and fat content of products, with points deducted from the score for protein, fibre, fruit, nut and vegetable content. The scores are used to classify products as either healthy or unhealthy. FSA scoring has been evaluated and found to have reasonable specificity and sensitivity, equivalent to that of other tools ${ }^{(31)}$. The upper maximum of the FSA scoring is 27 points, indicating a very unhealthy product. For example, hot cross buns would be classified as healthy because they have a relatively low proportion of fats and 
sugars by weight, with enough fruit and fibre to score 'positive' points on the scoring system, giving them a total score of 0 . Most chocolate bars have a high proportion of sugars, fats and salt by weight, and not enough fruit or fibre to score 'good' points, so they would typically score 26-27 on the FSA scale.

Using FSA scores, the proportion of unhealthy products out of all product ranges displayed to children at or below the eye-level of a 5-year-old was calculated for each supermarket. Where calculation of the FSA score for a product was not possible because sufficient nutritional data were not able to be found, these were listed as unclassified. Non-food products were also considered unclassifiable. Unclassifiable products were excluded from calculation of the proportion of healthy products.

The distribution of the scores was examined, and since this was skewed towards the unhealthy end of the score range, median scores for each store were used rather than mean scores. A high proportion of the products displayed that were classified as healthy were brands of sugar-free chewing gum, which has very little nutritional value. Sensitivity analysis was performed to calculate the proportion of healthy products on display when sugar-free gum was excluded from the analysis.

The 2010 Index of Multiple Deprivation (IMD) score and the ranking for the supermarkets' Lower Super Output Area were also obtained from the Office of National Statistics website $^{(32)}$ using the stores' postcode. Pearson's correlation coefficient was calculated for the following relationships:

1. The relationship between the IMD rank and median FSA score (including and excluding sugar-free gum).

2. The relationship between the IMD rank and the proportion of healthy products on display when excluding sugar-free gum.

Because one of the stores was obviously an outlier, sensitivity analysis was used to recalculate these values excluding this store.

Using a two-tailed test, $P$ values for the correlation coefficients were calculated using the method described by Lowry ${ }^{(33)}$. Again, this was repeated excluding the outlier store.

\section{Ethical considerations}

This research did not involve human subjects. Store managers were asked for permission to carry out the research. They were informed that their store would not be specifically identified in the findings. All managers willingly gave consent to be surveyed.

\section{Results}

The overwhelming majority of products on display were unhealthy, as displayed in Table 1. Products tended to score towards the upper end of the range of scores

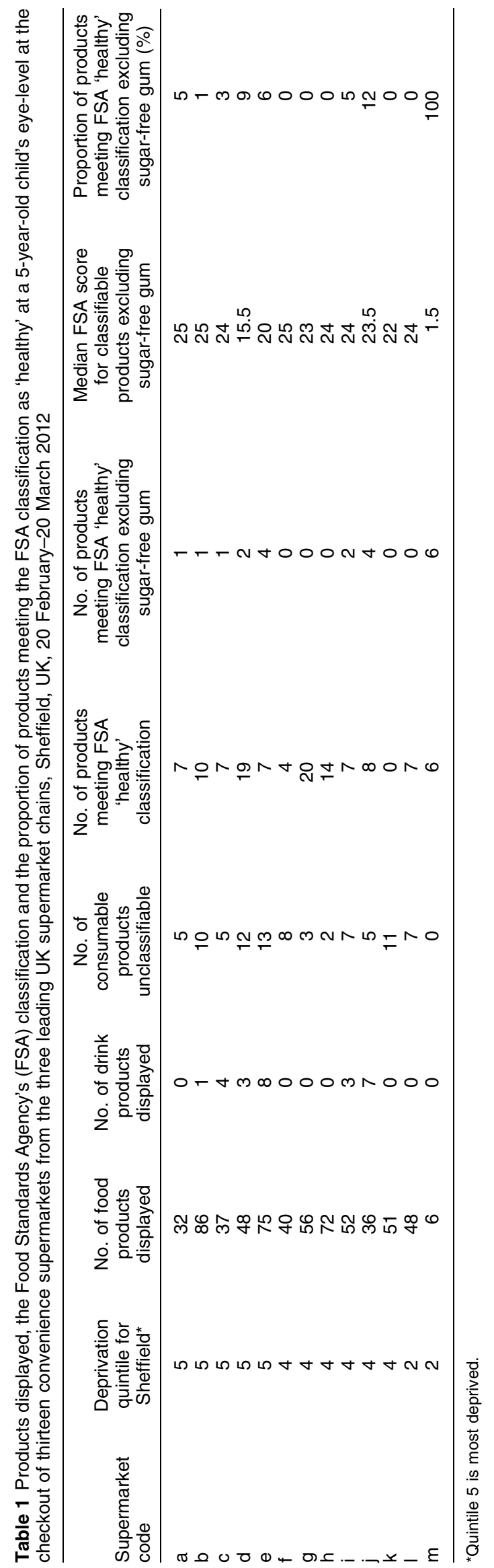


available on the FSA profiles, meaning that not only were they classified as unhealthy but they also tended to have high contents of all three unhealthy components (saturated fats, sugar and salt).

On average $13 \%$ of food or drink products could not be classified by FSA standards as their nutritional information was not available online. Most of these were specialty Easter products, or cough sweets. Non-food items on display at this height tended to be tissues, hand sprays, overthe-counter medications like antacids, paracetamol and ibuprofen, and beer. There were also a number of combination products where toys were combined with edible products, which were not able to be classified as nutritional information for the food products was not available.

As Table 1 shows, for most stores the only products they displayed which achieved a healthy classification were brands of sugar-free chewing gum. With one notable exception, stores had very few healthy products on display.

One store was obviously a significant outlier, displaying only six products, all of which were healthy. These were all packages of dried fruit and nuts. When the surveyors questioned the manager about the display, the manager declared that he was following a suggested policy from the supermarket chain's owners.

Table 1 also shows the IMD scores for the convenience supermarkets. The majority of the convenience supermarkets were in the most deprived or the second most deprived quintile, i.e. the less affluent areas of town. There was a moderate negative relationship between IMD rank and the median FSA score for classifiable products when sugar-free gum was excluded (Pearson's $r=-0.59$, $P=0 \cdot 033$ ), suggesting that stores in the more deprived areas displayed more unhealthy products. The relationship between the proportion of healthy products displayed and IMD rank was similar (Pearson's $r=0 \cdot 63, P=0 \cdot 020$ ), suggesting the stores in the least deprived areas displayed the highest proportion of healthy products.

The only store not to display any unhealthy foods was in the most affluent of the areas we investigated. Considering this store as an outlier and excluding it from analysis showed no correlation between IMD rank and the median FSA score excluding sugar-free gum (Pearson's $r=0 \cdot 06, P=0 \cdot 842$ ). There was also no relationship between the IMD rank and the proportion of healthy products displayed (Pearson's $r=-0 \cdot 27, \quad P=0 \cdot 38$ ). These results suggest that any relationship seen between deprivation and the healthiness of products displayed was due to the influence of this outlier store.

\section{Discussion}

The present study is the first one we know of to analyse the display of unhealthy foodstuffs to children at the checkout area of convenience supermarkets. The study found that on average $89 \cdot 5 \%$ of food products on display to children in convenience supermarkets were unhealthy, and that in most cases foodstuffs on display were at the upper end of the spectrum of unhealthy foodstuffs. This is despite supermarkets and the food industry having joined the UK Government in contributing to policy and producing 'responsibility deals' to reduce childhood obesity levels ${ }^{(34)}$.

This was a relatively small study conducted in one city. Only relatively central, urban convenience stores were considered. This means that applicability of the study to other cities or more rural convenience stores is limited.

Chewing gum was a commonly offered product at the height limit we chose. Sugar-free gum can be considered a consumable product, and under the FSA classifications it would be deemed healthy. This is a debatable definition, so we undertook sensitivity analysis to see what impact calling sugar-free gum a healthy product had on the results. Excluding sugar-free gum from the analysis revealed that very few products were healthy. Future research will need to consider in advance how chewing gum products are classified.

The study occurred in the month prior to Easter. This is a recognised limitation of the study, as chocolate products may be more prominent during this period. Safeway supermarket chain has previously commented that it makes exceptions to its checkout display policies during certain times of the year, such as Easter, Christmas and Mother's Day ${ }^{(19)}$. It is uncertain how much the timing influenced the study's results.

The present study used a height limit to estimate which products children would be directly exposed to. This limits the applicability of the study to adults, although in practice few of the stores had displays much higher than $1 \mathrm{~m}$. The height limit also reduces applicability to children sitting in trolleys, but as the use of trolleys is relatively rare in convenience stores we have not accounted for this.

Nutritional information was not available on the Internet for a significant number of products. The percentage of unhealthy products would probably have been even higher if nutritional information was available for all products, since most of those that could not be accurately classified were specialty chocolate-related lines in stores for Easter. We did not attempt to extrapolate data purely from chocolate products as many of the Easter products combined more than one type of confectionery or combined food with non-food items. This may be seen as a weakness of the study; however, the authors believe the decision only to analyse products where FSA classification was possible adds to the study's robustness.

We attempted to examine the relationship between deprivation in the area surrounding the supermarket and the healthiness of products displayed. While we found a significant correlation, our study was inadequately powered to investigate this conclusively. Sensitivity analysis showed that the relationship discovered is probably the result of the one outlier store which displayed only healthy products, and no conclusions can be drawn from our research. 
All three supermarket chains surveyed in the present study signed up to the pledge in March 2011 to 'support and enable our customers to eat and drink fewer calories through actions such as product/menu reformulation, reviewing portion sizes, education and information, and actions to shift the marketing mix towards lower calorie

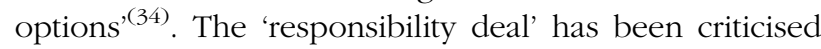
by many health groups as lacking in enforcement options and having no obvious process of accountability or sanctions for failing to deliver on pledges ${ }^{(35)}$.

Our decision to measure only products at or below $1 \mathrm{~m}$ above the floor height potentially underestimates the number of products children are exposed to. Older children may be able to see and reach products higher up.

As an incidental finding, we found over-the-counter medications displayed at the checkout within the reach of children. Displayed alongside confectionery, these could potentially present a danger to children if they picked them up unobserved. This would be an interesting avenue for future research.

The present study has important implications for policy makers seeking to arrest the rise in childhood obesity. Further research should assess the impact of the 'responsibility deal' on accessibility of unhealthy foods to children. It should also aim to establish a recurrent survey to examine the trend of exposure.

\section{Conclusions}

Convenience supermarkets from the three major chains in central Sheffield are exposing children to high-energy, unhealthy foodstuffs at the checkout area. There are isolated examples of good practice though, with one store offering only healthy products at the checkout. This research did not demonstrate any convincing evidence of a relationship between deprivation in the area surrounding the convenience store and the proportion of healthy foods on display. The impact of government interventions like the 'responsibility deal' with industry will need to be evaluated to see if there is any impact on these displays.

\section{Acknowledgements}

Sources of funding: This research received no specific grant from any funding agency in the public, commercial or not-for-profit sectors. Conflicts of interest: None. Ethics: Ethical approval was not required as the study did not involve human subjects. Authors' contributions: J.A.H. initiated the project, collated the data, drafted and revised the paper. He is the guarantor. All authors were involved in the design of the study protocol. R.J.D., A.M.F., E.M.A. and K.A.R.A. collected and entered the initial data. J.H. checked the data. All authors helped produce the database of products' FSA values.

\section{References}

1. Aronne LJ, Nelinson DS \& Lillo JL (2009) Obesity as a disease state: a new paradigm for diagnosis and treatment. Clin Cornerstone 9, 9-25.

2. Bundred P, Kitchiner D \& Buchan I (2001) Prevalence of overweight and obese children between 1989 and 1998: population based series of cross sectional studies. BMJ 322, 326-328.

3. Rudolf MCJ, Sahota P, Barth J et al. (2001) Increasing prevalence of obesity in primary school children: cohort study. BMJ 322, 1094-1095.

4. Chinn S \& Rona RJ (2001) Prevalence and trends in overweight and obesity in three cross sectional studies of British children, 1974-94. BMJ 322, 24-26.

5. Metcalf BS, Hosking J, Jeffery AN et al. (2011) Fatness leads to inactivity, but inactivity does not lead to fatness: a longitudinal study in children (EarlyBird 45). Arch Dis Child 96, 942-947.

6. Serdula MK, Ivery D, Coates RJ et al. (1993) Do obese children become obese adults? A review of the literature. Prev Med 22, 167-177.

7. Must A (1996) Morbidity and mortality associated with elevated body weight in children and adolescents. Am J Clin Nutr 63, 3 Suppl., 445S-447S.

8. Dietz WH (1998) Health consequences of obesity in youth: childhood predictors of adult disease. Pediatrics 101, 518-525.

9. World Health Organization (2003) Diet, Nutrition, and the Prevention of Chronic Diseases: Report of a Joint WHO/ FAO Expert Consultation. http://whqlibdoc.who.int/trs/ who_trs_916.pdf (accessed June 2013).

10. Linn S \& Novosat CL (2008) Calories for sale: food marketing to children in the twenty-first century. Ann Am Acad Polit Soc Sci 615, 133-155.

11. Carter OBJ, Patterson LJ, Donovan RJ et al. (2011) Children's understanding of the selling versus persuasive intent of junk food advertising: implications for regulation. Soc Sci Med 72, 962-968.

12. Marshall D, O'Donohoe S \& Kline S (2007) Families, food, and pester power: beyond the blame game? J Consum Behav 6, 164-181.

13. Buijzen M \& Valkenburg PM (2008) Observing purchaserelated parent-child communication in retail environments: a developmental and socialization perspective. Hum Commun Res 34, 50-69.

14. Dixon H, Scully M \& Parkinson K (2006) Pester power: snackfoods displayed at supermarket checkouts in Melbourne, Australia. Health Promot J Aust 17, 124-127.

15. Thornton LE, Cameron AJ, McNaughton SA et al. (2012) The availability of snack food displays that may trigger impulse purchases in Melbourne supermarkets. BMC Public Health 12, 194.

16. Miller C, Bodor JN \& Rose D (2012) Measuring the food environment: a systematic technique for characterizing food stores using display counts. J Environ Public Health 2012, 707860 .

17. Children's Food Campaign (2012) Checkouts checked out - How supermarkets and high street stores promote junk food to children and their parents. http://www.sustainweb. org/publications/?id=212 (accessed September 2013).

18. The Institute of Grocery Distribution (2012) Convenience Retailing Market Overview. http://www.igd.com/ourexpertise/Retail/Convenience/3369/Convenience-RetailingMarket-Overview/ (accessed June 2013).

19. The Food Commission (2003) Supermarkets told to Chuck snacks off the checkout! http://www.foodcomm.org.uk/ articles/checkout_snacks/ (accessed July 2013).

20. The Food Commission (2005) Checkouts still failing the junk test. http://www.foodcomm.org.uk/articles/checkouts_ and_junk/ (accessed July 2013). 
21. The Food Commission (2009) Chuck Snacks off the Checkout. Published in The Food Magazine 28th September 2009. http://www.foodcomm.org.uk/articles/chuck_snacks_ off_checkout/ (accessed September 2013).

22. Chapman K, Nicholas P, Banovic D et al. (2006) The extent and nature of food promotion directed to children in Australian supermarkets. Health Promot Int 21, 331-339.

23. Campbell S, James EL, Stacey FG et al. (2012) A mixedmethod examination of food marketing directed towards children in Australian supermarkets. Health Promot Int (Epublication ahead of print version).

24. Vinkeles Melchers NVS, Gomez M \& Colagiuri R (2009) Do socio-economic factors influence supermarket content and shoppers' purchases? Health Promot J Aust 3, 241-246.

25. Cameron AJ, Thornton LE, McNaughton SA et al. (2013) Variation in supermarket exposure to energy-dense snack foods by socio-economic position. Public Health Nutr 16, $1178-1185$.

26. Sheffield City Council (2012) Sheffield Population Estimates 2011. https://www.sheffield.gov.uk/SCC-Home/your-citycouncil/sheffield-profile/population-and-health/populationestimates (accessed November 2013).

27. Freeman J V, Cole TJ, Chinn S et al. (1995) Cross sectional stature and weight reference curves for the UK, 1990. Arch Dis Child 73, 17-24.
28. Curhan RC (1973) Shelf space allocation and profit maximization in mass retailing. J Mark 37, 54-60.

29. Mehta K, Phillips C, Ward P et al. (2012) Marketing foods to children through product packaging: prolific, unhealthy and misleading. Public Health Nutr 15, 1763-1770.

30. Department of Health (2011) Nutrient Profiling Technical Guidance. https://www.gov.uk/government/uploads/system/ uploads/attachment_data/file/216094/dh_123492.pdf (accessed September 2013).

31. Quinio C, Biltoft-Jensen A, De Henauw S et al. (2007) Comparison of different nutrient profiling schemes to a new reference method using dietary surveys. Eur J Nutr 46, Suppl. 2, 37-46.

32. Office for National Statistics (2010) 2010 Index of Multiple Deprivation. http://neighbourhood.statistics.gov.uk/dissemination/ (accessed July 2013).

33. Lowry R (not dated) Concepts and Applications of Inferential Statistics. The Significance of a Correlation Coefficient. http:// vassarstats.net/textbook/ch4apx.html (accessed November 2013).

34. Department of Health (2011) Public Health Responsibility Deal. http://responsibilitydeal.dh.gov.uk/ (accessed September 2013).

35. BBC News (2011) More groups reject health deal as pledges are unveiled. http://www.bbc.co.uk/news/health-12737200 (accessed September 2013). 